\title{
Murraya paniculata and Related Species as Potential Hosts and Inoculum Reservoirs of 'Candidatus Liberibacter asiaticus', Causal Agent of Huanglongbing
}

\author{
V. D. Damsteegt, E. N. Postnikova, and A. L. Stone, Foreign Disease-Weed Science Research Unit, ARS, USDA, \\ Frederick, MD 21702; M. Kuhlmann, University of Maryland, College Park; C. Wilson, University of Wisconsin, \\ Madison; A. Sechler and N. W. Schaad, Foreign Disease-Weed Science Research Unit, ARS, USDA, Frederick, MD \\ 21702; R. H. Brlansky, CREC, IFAS, UFL, Lake Alfred, FL 33850; and W. L. Schneider, Foreign Disease-Weed \\ Science Research Unit, ARS, USDA, Frederick, MD 21702
}

\begin{abstract}
Damsteegt, V. D., Postnikova, E. N., Stone, A. L., Kuhlmann, M., Wilson, C., Sechler, A., Schaad, N. W., Brlansky, R. H., and Schneider, W. L. 2010. Murraya paniculata and related species as potential hosts and inoculum reservoirs of 'Candidatus Liberibacter asiaticus', causal agent of Huanglongbing. Plant Dis. 94:528-533.

Huanglongbing (HLB), considered to be the most serious insect-vectored bacterial disease of citrus, is transmitted in nature by the Asian citrus psyllid Diaphorina citri and the African citrus psyllid Trioza erytreae. D. citri was discovered in southern Florida in 1998 and the HLB disease in 2005. Both have become established throughout citrus-producing areas of Florida. Murraya species are widely grown in southern Florida as ornamental hedges and are readily colonized by D. citri vectors. Colonies of $D$. citri, isolates of 'Candidatus Liberibacter asiaticus' from Taiwan and Florida, and the Murraya species were established in the BSL-3 biosecurity facility at Fort Detrick. In controlled inoculation experiments, $D$. citri transmitted ' $C a$. L. asiaticus' into $M$. paniculata (34/36 plants) and M. exotica (22/23 plants), but not into Bergera (Murraya) koenigii. Disease symptoms rarely developed in Murraya plants; however, positive infections were determined by conventional and real-time polymerase chain reaction (PCR). Back-inoculations of ' $\mathrm{Ca}$. L. asiaticus' from $\mathrm{M}$. paniculata to Madam Vinous sweet orange resulted in disease development in $25 \%$ of the inoculated plants. Considerable variability was observed in infection rates, titer, and persistence of ' $\mathrm{Ca}$. L. asiaticus' in infected Murraya.
\end{abstract}

Huanglongbing (HLB) is considered to be the most destructive insect-vectored disease of citrus. Previously known as citrus greening, the disease, known to be phloem-limited, is associated with a fastidious, gram-negative bacterium belonging to the alpha subdivision of the Proteobacteria ('Candidatus Liberibacter' spp.) (7) that recently has been cultured $(10,27)$ and is transmitted by psyllids, grafting, and dodder. Reinking's description of a disease supposed to be HLB in China (26) is commonly cited as the first description; however, a much more detailed description of tree symptoms associated with psyllid infestations in India may be a more authentic first description (17). The psyllid vectors and HLB have been spreading to new areas of the world $(7,9)$. There are three purported bacterial species, ' $\mathrm{Ca}$. L. africanus', ' $C a$. L. asiaticus', and ' $C a$. L.

Corresponding author: V. D. Damsteegt

E-mail: vern.damsteegt@ars.usda.gov

Accepted for publication 31 December 2010.

doi:10.1094/PDIS-94-5-0528

This article is in the public domain and not copyrightable. It may be freely reprinted with customary crediting of the source. The American Phytopathological Society, 2010. americanus' (7). The psyllid species Trioza erytreae (del Guercio) (African citrus psyllid) is associated with transmission of ' $C a$. L. africanus' and is restricted by temperatures above $30^{\circ} \mathrm{C}$, whereas Diaphorina citri Kuwayama (Asian citrus psyllid) is more tolerant of higher temperatures (above $30^{\circ} \mathrm{C}$ ) and principally associated with transmission of ' $\mathrm{Ca}$. L. asiaticus' and ' $\mathrm{Ca}$. L. americanus' (7). The Asian citrus psyllid cannot withstand long periods of cold temperature $\left(\sim 5.0^{\circ} \mathrm{C}\right)(15)$.

The Asian citrus psyllid has been known in Brazil for more than 60 years (21) and was discovered in Florida in 1998 (12). Despite continuous surveillance in Brazil, HLB was never observed until 2004 in the state of São Paulo (29). Following the discovery of an infestation of $D$. citri in Palm Beach, FL in 1998, efforts to find HLB in Florida resulted in the discovery of HLB-infected citrus trees in 2005 (13). Despite immediate implementation of high priority surveys for $D$. citri and HLB infected trees, both continued to spread throughout the citrus growing areas of Florida. In addition, D. citri subsequently spread to Texas in 2001 (11), Louisiana in 2007 (1), Baja California (Mexico) in 2004 (confirmed in 2008), and Southern California, Alabama, Georgia, Mississippi, and South Carolina in 2008 (2). HLB ('Ca. L. asiaticus') recently has been reported in Louisiana (1), Georgia, South Carolina (3), Yucatan, Mexico (4), Jamaica (5), Belize (British Honduras) (23), and Puerto Rico (6).

The natural host range of ' $\mathrm{Ca}$. L. asiaticus' includes species in the Rutaceae family with severe symptoms mainly in sweet oranges, mandarins, tangelos, and grapefruit (14). Some non-Rutaceous species such as Nicotiana tabacum and Lycopersicon esculentum have been experimentally infected with HLB-associated bacteria using dodder (14). The ornamental Rutaceous species, Murraya paniculata (L.) Jack (Jasmine orange, Orange Jessamine), M. exotica L., and Bergera (Murraya) koenigii (L.) Sprengel (Curry leaf, Curry tree, Sweet Neem leaf), are commonly grown in citrus production areas and have been shown to be good hosts of the Asian citrus psyllid $(14,16)$. This has raised concern about the role these plants might play as potential hosts and/or reservoirs for the HLB pathogen. M. paniculata has been reported as a host of ' $\mathrm{Ca}$. L. asiaticus' and ' $\mathrm{Ca}$. L. americanus' through grafting and dodder transmission $(22,30)$.

Some taxonomic uncertainty exists concerning the correct classification of $M$. paniculata and M. exotica, although molecular evidence suggests that $M$. exotica may actually be a variety of $M$. paniculata, possibly $M$. paniculata var. ovatifoliolata $(18,25)$. Some reports list both species as synonymous, and other reports list them as separate species $(24,28)$. In addition, $M$. koenigii has been renamed to Bergera koenigii (18). The Murraya host and psyllid relationship is undisputable; however, the relationship between the Murraya species, D. citri, and 'Ca. Liberibacter' species has been widely speculated (14). The objectives of our research were to determine the susceptibility of different Murraya species to ' $\mathrm{Ca}$. L. asiaticus' and their possible potential to serve as inoculum hosts. We report here on the relationship of Murraya species and ' $\mathrm{Ca}$. L. asiaticus' as transmitted by $D$. citri.

\section{MATERIALS AND METHODS}

Acquisition and colonization. Asian citrus psyllids were collected in Florida in 1998 prior to the discovery of HLB, and a 
colony was established in a BSL-3 biosecurity containment facility at Fort Detrick on sweet orange (Citrus sinensis), Mexican lime (C. aurantifolia), M. paniculata, and $B$. koenigii. Two isolates of ' $\mathrm{Ca}$. L. asiaticus' (B239 from Taiwan and 10210 from Florida) were obtained from the ARS, USDA Beltsville Exotic Citrus Disease Collection (J. S. Hartung, USDA, Beltsville, MD) under APHIS and Maryland Department of Agriculture permits. Seedlings of $M$. paniculata, B. koenigii, and $M$. exotica were purchased from a commercial nursery in Danielson, CT. For this study, the plant identifications provided by the supplier were assumed to be accurate. The morphological differences between the Murraya and Bergera species are clearly distinguishable and consistent (Fig. 1). Citrus, Murraya, and Bergera seedlings were grown in insect-free greenhouses maintained at $25^{\circ} \mathrm{C}$ with daily fluctuations of 5 to $7^{\circ} \mathrm{C}$, and natural daylight with supplemental lighting. All test plants and psyllids used in this study were assayed for latent ' $\mathrm{Ca}$. L. asiaticus' infection by realtime polymerase chain reaction (PCR) prior to use in any experiment.

Inoculation procedure. Healthy six- to eight-leaf $M$. paniculata seedlings were inoculated by psyllid transmission 2 to 3 months after transplanting. D. citri adults, determined to be ' $\mathrm{Ca}$. L. asiaticus'-free by real-time PCR, were colonized on ' $\mathrm{Ca}$. $\mathrm{L}$. asiaticus'-infected Madam Vinous sweet orange for a 3-week acquisition access period (AAP). Although psyllids were mating and reproducing during the AAP, only adults were used for inoculations. Sets of 40 to 50 adult $D$. citri from infected sweet orange plants were transferred onto individual Murraya seedlings in $10 \times 30$ $\mathrm{cm}$ tubular plastic and saran single pot cages for a 14-day inoculation access period (IAP). Ten psyllids from the colony cage were assayed for the presence of ' $\mathrm{Ca}$. L. asiaticus' by real-time PCR at each inoculation throughout all experiments. Psyllids were counted when placed on Murraya spp., and when they were transferred from test plants. Samples of 6 to 10 psyllids were removed from each Murraya plant following the IAP and assayed for 'Ca. L. asiaticus' by real-time PCR. Sweet orange plants were inoculated using HLBinfected psyllids as positive controls, and healthy plants were mock-inoculated using healthy psyllids as negative controls with each experimental inoculation.

Following inoculation, plants were allowed to grow on the greenhouse bench (day length maintained at $16 \mathrm{~h}$ by supplemental lighting, temperature range $25^{\circ} \mathrm{C}$ night $/ 25$ to $32^{\circ} \mathrm{C}$ day), and were observed for symptoms. All M. paniculata plants were assayed by real-time PCR 2 months postinoculation (PI), and again 5, 10, 18, 24, and 32 months PI. A total of $36 \mathrm{M}$. paniculata plants were inoculated over a period of 15 months, 26 with the Taiwan- ese ' $C a$. L. asiaticus' isolate and 10 with the Florida isolate (Table 1).

Inoculation of B. koenigii was similar to that of M. paniculata, except that 60 to 75 psyllids were used to inoculate some plants. Psyllids were tested for the presence of ' $\mathrm{Ca}$. L. asiaticus' after a 14-day IAP on each B. koenigii plant and inoculated control sweet orange seedlings. All seedlings were assayed by real-time PCR 2 months PI and again 5 and 10 months PI. A total of 17 B. koenigii plants were inoculated over a period of 6 months.

Inoculation of $23 \mathrm{M}$. exotica plants was similar to that of M. paniculata, with 50 psyllids used as an inoculation set. For all experiments, Madam Vinous sweet orange seedlings were used as positive controls. All seedlings were assayed by real-time PCR 3 months PI and again at 7 months PI.
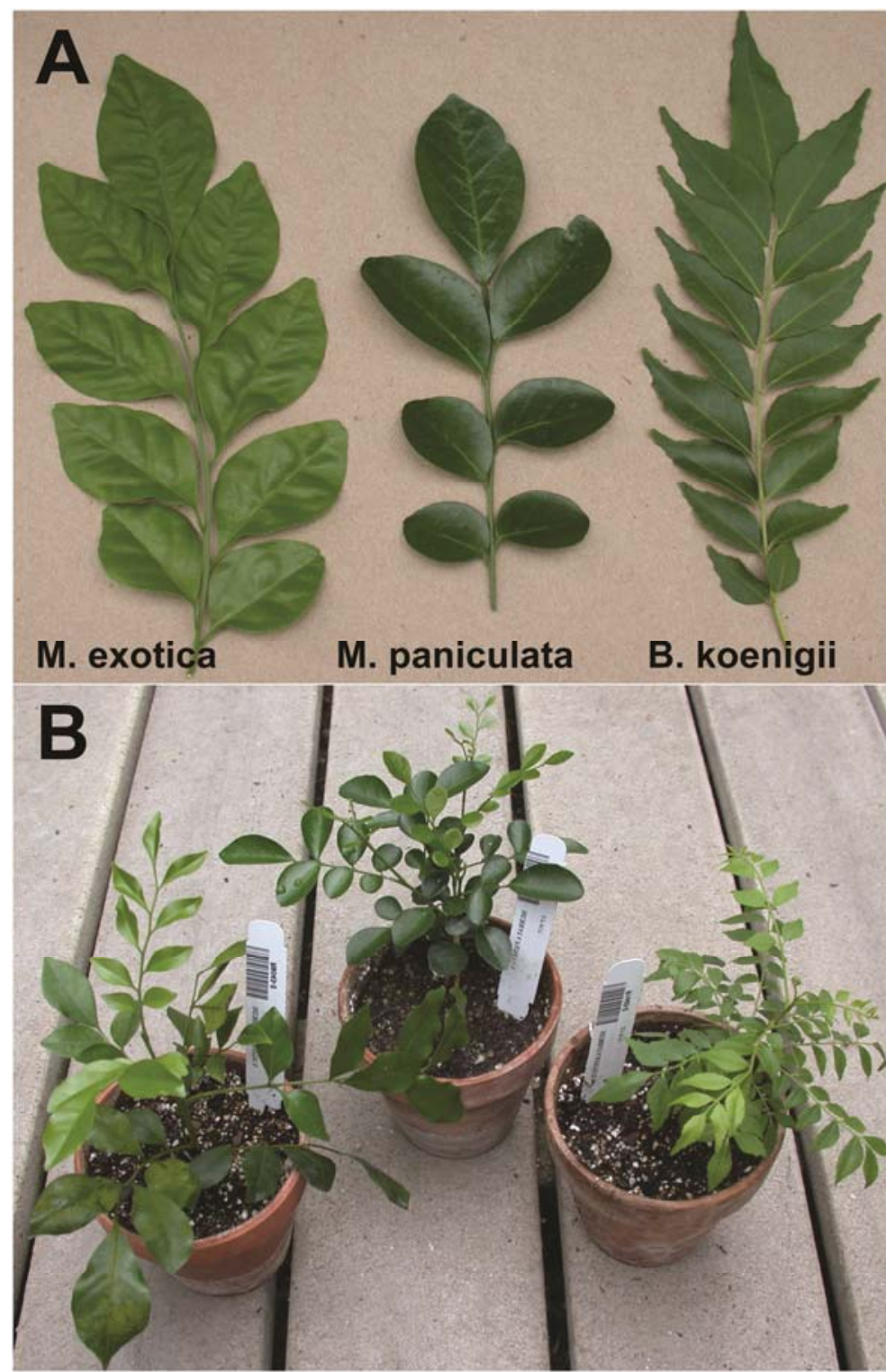

$\begin{array}{lll}\text { M. exotica } & \text { M. paniculata } & \text { B. koenigii }\end{array}$

Fig. 1. A, Leaf characteristics and B, plant growth characteristics for Murraya exotica, M. paniculata, and Bergera koenigii.
Inoculation assays. Individual Murraya and Bergera test plants were assayed by real-time PCR for the presence of ' $\mathrm{Ca}$. L. asiaticus'. Samples for assay were new leaves that had developed following inoculation to prevent detection of bacteria that had not moved from the inoculation site. DNA was extracted from inoculated plants using a modified DNeasy Plant Mini kit protocol (Qiagen, Germantown, MD). Briefly, newly formed leaves were aseptically removed, leaf lamina discarded, and midveins and petioles finely chopped with sterile razor blades. Twice the recommended amount of plant tissue was used for extraction $(200 \mathrm{mg})$, and the recommended amounts of AP1 and AP2 buffers were doubled. Psyllids were assayed for the presence of ' $C a$. L. asiaticus' by collecting batches of 6 to 10 psyllids from plant sources and freezing and pulverizing 
them in liquid nitrogen. DNA was extracted using the Qiagen DNeasy Plant Mini kit according to the manufacturer's protocol (Qiagen).

Real-time PCR was performed using previously published HLB primers and probes (20), and/or unpublished primers and probes developed in our laboratory utilizing the $16 \mathrm{~S}$ ribosomal gene of ' $\mathrm{Ca}$. L. asiaticus' as a target (Primers: HLBAsiaF1 5'-CTTACCAGCCCTTGACATGTATA-3' and HLBAsiaR1 5'-CATGCAGCACCT GTGTAAAG 3'; Probe HLBAsiaP1 5'dFAM-ACGATATCAGAGATGGTATTT TCTTTTCG-BHQ-1-3'). Internal controls were used as described by Li et al. (20). The real-time PCR protocol for the HLBAsia primer and probe set was as follows: $95^{\circ} \mathrm{C}$ for $20 \mathrm{~s}$ followed by 60 cycles at $95^{\circ} \mathrm{C}$ for $1 \mathrm{~s}$ and $60^{\circ} \mathrm{C}$ for $20 \mathrm{~s}$. PCR reactions contained $10 \mu \mathrm{l}$ of $2 \times$ Master Mix, $5.5 \mu \mathrm{l}$ of PCR grade water, $1 \mu \mathrm{l}$ of each $100 \mu \mathrm{m}$ primer stock, $0.5 \mu \mathrm{l}$ of 100 $\mu \mathrm{M}$ probe stock, and $2 \mu \mathrm{l}$ of DNA template (Applied Biosystems, Carlsbad, CA). Both primer and probe sets generated very simi- lar cycle threshold $(\mathrm{Ct})$ values, and only the HLBAsia assay results are presented. Some of the real-time PCR-positive plants were confirmed by cloning and sequencing the ' $C a$. L. asiaticus' intergenic spacer (ITS) region obtaining an expected size (approximately $900 \mathrm{bp)} \mathrm{product,} \mathrm{using}$ previously described primers and amplification protocols (19) and the Topoclone TA kit (Invitrogen, Carlsbad, CA) according to manufacturer protocols. Plasmids were sequenced using an ABI $3100 \mathrm{Ge}$ netic Analyzer (Applied Biosystems), and sequences were aligned and analyzed using Codon Code aligner (CodonCode, Dedham, MA). Quality of DNA extraction was checked using host primer and probes as previously described (20).

Back-assay inoculations of ' $\mathrm{Ca}$. L. asiaticus' from $M$. paniculata to sweet orange with psyllids were attempted with several plants, eliciting an arbitrarily chosen initial real-time PCR Ct value less than 36 . No back-assays were attempted from $B$. koenigii or $M$. exotica plants, or $M$. paniculata plants with $\mathrm{Ct}$ values above 36 .
Healthy psyllids (assayed by PCR) were transferred in sets of 40 to individual infected Murraya plants in tubular cages for a 14-day AAP. Samples of 6 to 10 psyllids were collected for assay at the end of each AAP, and the remaining psyllids were placed on small healthy Madam Vinous seedlings for a 14-day IAP. After 2 weeks, all surviving psyllids on the test orange plants were collected and assayed by realtime PCR for ' $C a$. L. asiaticus' bacteria. Back-assay inoculated orange plants were placed on the greenhouse bench for symptom development and assayed by PCR 3 and 22 months PI. Visible symptoms of HLB infection, if present, were recorded.

\section{RESULTS}

All psyllid colonies were free of ' $C a$. L. asiaticus' prior to placement on infected sweet orange plants. After feeding and multiplying on HLB-infected sweet orange for at least 3 weeks, samples of 10 psyllids tested by real-time PCR gave evidence of having acquired high levels of ' $\mathrm{Ca}$. L. asiaticus', with $\mathrm{Ct}$ values ranging from

Table 1. Reaction of Murraya paniculata to inoculation with 'Candidatus Liberibacter asiaticus' following vector transmission by Diaphorina citri

\begin{tabular}{|c|c|c|c|c|c|c|c|c|}
\hline $\begin{array}{l}\text { M. paniculata } \\
\text { test plant no. }\end{array}$ & $\begin{array}{l}\text { No. D. citri } \\
\text { on/off }{ }^{\mathrm{b}}\end{array}$ & $\begin{array}{c}\text { D. citri } \\
\text { post-IAP Ct }\end{array}$ & $\begin{array}{c}\text { Plant assay } 1 \\
\text { 2-month PI } \\
\left(_{(\mathrm{Ct})^{\mathrm{d}}}\right.\end{array}$ & $\begin{array}{c}\text { Plant assay } 2 \\
\text { 5-month PI } \\
(\mathrm{Ct})^{\mathrm{e}}\end{array}$ & $\begin{array}{l}\text { Plant assay } 3 \\
\text { 10-month PI } \\
\text { (Ct) }\end{array}$ & $\begin{array}{c}\text { Plant assay } 4 \\
\text { 18-month PI } \\
\text { (Ct) }\end{array}$ & $\begin{array}{c}\text { Plant assay } 5 \\
\text { 24-month PI } \\
\text { (Ct) }\end{array}$ & $\begin{array}{l}\text { Plant assay } 6 \\
\text { 32-month PI } \\
(\mathrm{Ct})^{\mathrm{f}}\end{array}$ \\
\hline 1 & $50 / 37$ & 31.4 & 35.2 & 36.8 & 45.2 & 0.0 & 0.0 & \\
\hline 2 & $50 / 43$ & 36.4 & 33.4 & $\ldots$ & 0.0 & 37.1 & 0.0 & \\
\hline 3 & $50 / 50$ & 36.3 & 34.8 & $\begin{array}{l}\cdots \\
\ldots\end{array}$ & 49.1 & 0.0 & & \\
\hline 4 & $50 / 37$ & 33.7 & 32.8 & 0.0 & & & & \\
\hline 5 & $50 / 32$ & 36.3 & 32.0 & $\ldots$ & 31.8 & 0.0 & 0.0 & \\
\hline 6 & $50 / 37$ & 30.7 & 33.4 & $\ldots$ & 32.1 & 0.0 & 0.0 & 37.8 \\
\hline 7 & $50 / 40$ & 33.3 & 36.0 & $\ldots$ & 37.6 & 0.0 & 0.0 & 0.0 \\
\hline 8 & $50 / 11$ & 39.1 & 34.0 & $\ldots$ & 37.5 & 0.0 & 0.0 & 35.9 \\
\hline 9 & $50 / 37$ & 35.1 & 31.2 & 39.6 & $\ldots$ & 0.0 & 0.0 & 40.2 \\
\hline 10 & $50 / 29$ & 34.2 & 34.5 & 35.9 & 34.1 & 0.0 & 0.0 & 0.0 \\
\hline 11 & $50 / 49$ & 0.0 & 0.0 & 0.0 & & & & \\
\hline 12 & $50 / 50$ & 21.8 & 34.9 & 39.2 & 38.5 & 0.0 & 0.0 & \\
\hline 13 & $50 / 46$ & 0.0 & 0.0 & & & & & \\
\hline 14 & $50 / 50$ & 33.7 & $\ldots$ & 32.1 & $\ldots$ & & & \\
\hline$* 15$ & $50 / 39$ & 17.5 & 29.1 & 37.5 & $\ldots$ & 0.0 & $\ldots$ & 0.0 \\
\hline$* 16$ & $50 / 13$ & 29.3 & 32.7 & 0.0 & 39.3 & 0.0 & $\ldots$ & 0.0 \\
\hline$* 17$ & $50 / 25$ & 36.4 & 0.0 & 0.0 & 38.1 & 0.0 & 0.0 & 38.1 \\
\hline$* 18$ & $50 / 26$ & 36.3 & 0.0 & 0.0 & 36.9 & 0.0 & 0.0 & \\
\hline$* 19$ & $50 / 31$ & 24.6 & 0.0 & 0.0 & 37.4 & 0.0 & 40.3 & 0.0 \\
\hline$* 20$ & $50 / 12$ & 32.7 & 0.0 & 0.0 & 37.1 & 0.0 & 0.0 & \\
\hline$* 21$ & $50 / 34$ & 18.1 & 32.6 & 0.0 & 32.9 & 0.0 & 0.0 & 37.5 \\
\hline$* 22$ & $50 / 32$ & 25.8 & 32.9 & 36.3 & 31.6 & 0.0 & 40.4 & 0.0 \\
\hline$* 23$ & $50 / 36$ & 28.8 & 31.2 & 38.9 & 36.1 & 0.0 & 0.0 & 37.9 \\
\hline$* 24$ & $50 / 38$ & 0.0 & 0.0 & 0.0 & 37.1 & 0.0 & 0.0 & 37.9 \\
\hline 25 & $40 / 18$ & $\ldots$ & 34.1 & 35.7 & 38.6 & 0.0 & $\ldots$ & 38.7 \\
\hline 26 & $40 / 17$ & 34.2 & 35.7 & 0.0 & 37.1 & $\ldots$ & 0.0 & 38.2 \\
\hline 27 & $40 / 19$ & 34.2 & 0.0 & 37.1 & 0.0 & 0.0 & $\ldots$ & 0.0 \\
\hline 28 & $50 / 46$ & 19.8 & 32.1 & 35.1 & 0.0 & 0.0 & $\ldots$ & 0.0 \\
\hline 29 & $50 / 41$ & 19.9 & 29.9 & 36.6 & 0.0 & $\ldots$ & $\ldots$ & 0.0 \\
\hline 30 & $50 / 43$ & 19.7 & 29.9 & 35.8 & 0.0 & 0.0 & $\ldots$ & 41.1 \\
\hline 31 & $50 / 51$ & 20.5 & 36.4 & 37.3 & 40.1 & 0.0 & & \\
\hline 32 & $50 / 48$ & 17.1 & 35.8 & 35.9 & 0.0 & 39.6 & 0.0 & \\
\hline 33 & $50 / 49$ & 16.7 & 34.8 & $\ldots$ & 0.0 & 0.0 & $\ldots$ & 39.4 \\
\hline 34 & $50 / 41$ & 14.4 & 33.4 & $\ldots$ & $\ldots$ & 0.0 & $\ldots$ & 0.0 \\
\hline 35 & $50 / 30$ & 15.6 & 34.1 & 0.0 & 40.5 & $\ldots$ & $\ldots$ & 35.1 \\
\hline 36 & $50 / 46$ & 17.3 & 35.9 & 38.1 & 0.0 & 0.0 & & \\
\hline
\end{tabular}

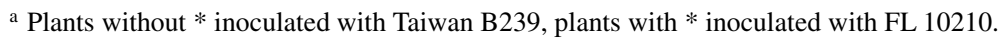

${ }^{\text {b }}$ D. citri transferred onto $M$. paniculata for 14-day inoculation access period (IAP)/surviving D. citri after 14 days.

${ }^{\text {c }}$ Real-time polymerase chain reaction (PCR) cycle threshold $(\mathrm{Ct})$ value for D. citri following IAP on M. paniculata.

${ }^{\mathrm{d}}$ Real-time PCR assay of M. paniculata 2 months postinoculation (PI).

e $\ldots=$ No real-time PCR assay data point.

${ }^{\mathrm{f}}$ Empty box means plant died or was discarded. 
14.4 to 22.1 (data not shown). The infected psyllids were used to inoculate the Murraya and Bergera test plants and sweet orange plants. The positive control orange plants used with all experiments typically presented $\mathrm{Ct}$ values ranging from 22 to 32 (average 24.6) and negative control orange plants remained HLB free (data not shown).

M. paniculata inoculations. Following the 14-day IAP on $M$. paniculata, samples of 6 to 10 surviving psyllids were assayed for the presence of ' $\mathrm{Ca}$. L. asiaticus'. Levels in these remaining psyllids were highly variable $(\mathrm{Ct}$ values ranged from 14.4 to 39.1 ; in three instances, no ' $\mathrm{Ca}$. L. asiaticus' was detected) (Table 1). Initial assay results of inoculated $M$. paniculata indicated that not all plants became infected, and bacterial levels were lower than in sweet orange, as evidenced by consistently higher $\mathrm{Ct}$ values. With most plants, the level of ' $\mathrm{Ca}$. L. asiaticus' in $\mathrm{M}$. paniculata coincided with the level in the psyllids that had fed on them, as measured by $\mathrm{Ct}$ values (Table 1). In a few plants, the post-IAP psyllids were positive for ' $\mathrm{Ca}$. L. asiaticus' while no bacteria were detected in the test plants after 2 months (Table 1).

$M$. paniculata plants were maintained on the bench for up to 32 months PI, during which time they were observed for symptoms and tested periodically for the presence of ' $\mathrm{Ca}$. L. asiaticus' by real-time PCR (Table 1). Some inoculated M. paniculata plants grew slowly with small leaves, while others had yellow leaves and raised veins. However, these abnormal plant reactions did not correspond to positive PCR results, suggesting the plant reactions were not directly related to infection. Control plants also were tested periodically for the presence of ' $C a$. L. asiaticus' bacteria. The inoculated Madam Vinous sweet orange positive controls had Ct values ranging from 22.1 to 32.2 ; mockinoculated $M$. paniculata with ' $C a$. L. asiaticus'-free psyllids had $\mathrm{Ct}$ values in the high 50 s, or ' $C a$. L. asiaticus' was not detected; and no ' $\mathrm{Ca}$. L. asiaticus' was detected in sweet orange negative controls (data not shown in Table 1). In total, 34 of $36 \mathrm{M}$. paniculata tested positive for ' $\mathrm{Ca}$. L. asiaticus' infection at some point in the experiment, indicating the presence of the bacteria in the plants. In the initial realtime PCR assay 2 months PI, 6 of 36 (16.7\%) M. paniculata plants had Ct values $<32,20$ of $36(55.6 \%)$ had $\mathrm{Ct}$ values from 32.1 to $36.0,1$ of $36(2.8 \%)$ had a $\mathrm{Ct}$ value of $36.4,8$ of $36(22.2 \%)$ had no detectable ' $\mathrm{Ca}$. L. asiaticus', and 1 of 36 (2.8\%) was not assayed at 2 months PI (Table 1). A number of the plants that originally tested negative (no detectable ' $C a$. L. asiaticus') tested positive in subsequent samplings in the 32-month PI period, and a number of plants that were positive (detectable ' $\mathrm{Ca}$. L. asiaticus') in the initial assay never tested positive again. M. paniculata plants never contained high levels of ' $\mathrm{Ca}$. L. asiaticus' (Ct values in the 30 s), and in most plants the levels of bacteria declined sharply after 3 to 5 months (Table 1). Although not all PCR-positive M. paniculata plants were cloned and sequenced, two (\#3 [Ct 34.8] and \#24 [Ct 29.9] Table 1) were confirmed to be ' $\mathrm{Ca}$. L. asiaticus'-positive by cloning and sequencing of the ' $\mathrm{Ca}$. L. asiaticus' ITS re- gion and blasting our sequences against ITS regions published in GenBank.

Four M. paniculata plants (numbers 1, 2,5 , and 36 in Table 1) initially had moderate ' $\mathrm{Ca}$. L. asiaticus' levels that declined over time. These were reinoculated 30 months after the first inoculation using infected psyllids. Reinoculations resulted in increased ' $\mathrm{Ca}$. L. asiaticus' levels (lower $\mathrm{Ct}$ values) for two of the four plants after 2 months (Table 2).

B. koenigii inoculations. Seventeen $B$. koenigii plants were inoculated with the Taiwan isolate of ' $\mathrm{Ca}$. L. asiaticus' using a similar experimental protocol. As in the $M$. paniculata experiments, psyllids acquired high levels of ' $\mathrm{Ca}$. L. asiaticus' after feeding on infected sweet orange (data not shown). However, 2 months PI, only four of 17 plants tested positive by real-time PCR (Table 3). In contrast, positive control orange plants inoculated by the same batch of psyllids were infected, with $\mathrm{Ct}$ values below 25 . The $\mathrm{Ct}$ values in the positive $B$. koenigii ranged from 32.2 to 40.2. All attempts to clone and sequence the ' $\mathrm{Ca}$. L.

Table 3. Reaction of Bergera koenigii to inoculation with 'Candidatus Liberibacter asiaticus' following vector transmission by Diaphorina citri

\begin{tabular}{cccccc}
\hline $\begin{array}{l}\text { B. koenigii } \\
\text { plant no. }\end{array}$ & $\begin{array}{c}\text { No. } \text {. } \text { citri } \\
\text { on/off }\end{array}$ & $\begin{array}{c}\text { D. citri } \\
\text { post-IAP } \\
\text { (Ct) }^{\mathbf{b}}\end{array}$ & $\begin{array}{c}\text { Plant assay 1 } \\
\text { 2-month PI } \\
\text { (Ct) }^{\mathbf{c}}\end{array}$ & $\begin{array}{c}\text { Plant assay 2 } \\
\text { 5-month PI } \\
(\mathbf{C t})^{\mathbf{d}}\end{array}$ & $\begin{array}{c}\text { Plant assay 3 } \\
\text { 10-month PI } \\
(\mathbf{C t})\end{array}$ \\
\hline 1 & $50 / 19$ & 34.7 & 0.0 & & \\
2 & $50 / 30$ & 36.8 & 0.0 & & \\
3 & $50 / 42$ & 21.7 & 0.0 & & \\
4 & $50 / 12$ & 35.5 & 0.0 & & \\
5 & $50 / 30$ & 21.3 & 32.2 & $\ldots$ & 0.0 \\
6 & $50 / 45$ & 21.1 & 36.7 & $\ldots$ & 0.0 \\
7 & $50 / 47$ & 27.2 & 32.3 & $\ldots$ & 0.0 \\
8 & $70 / 68$ & 16.9 & 0.0 & 0.0 & 0.0 \\
9 & $75 / 39$ & 16.9 & 0.0 & $\ldots$ & \\
10 & $75 / 65$ & 17.8 & 40.2 & $\ldots$ & \\
11 & $50 / 9$ & 21.2 & $\ldots$ & 0.0 & \\
12 & $50 / 41$ & 23.4 & $\ldots$ & 0.0 & \\
13 & $50 / 4$ & 22.5 & $\ldots$ & 0.0 & \\
14 & $50 / 15$ & 21.2 & 0.0 & 0.0 & \\
15 & $60 / 23$ & 25.3 & $\ldots$ & 0.0 & \\
16 & $60 / 38$ & 26.2 & $\ldots$ & 0.0 & \\
17 & $60 / 35$ & 22.4 & $\ldots$ & 0.0 & \\
\hline
\end{tabular}

a Number of $D$. citri transferred onto B. koenigii for 14 days/number of D. citri surviving after 14 days.

${ }^{\mathrm{b}}$ Real-time polymerase chain reaction (PCR) cycle threshold (Ct) value for D. citri following 14-day inoculation access period (IAP) on B. koenigii.

${ }^{c}$ Real-time PCR assay of B. koenigii 2 months postinoculation.

${ }^{\mathrm{d}}$ Empty box indicates plant died or was discarded; $\ldots=$ no real-time PCR assay data point.

Table 2. Reinoculation of Murraya paniculata with 'Candidatus Liberibacter asiaticus' 30 months following initial inoculation by the vector Diaphorina citri

\begin{tabular}{|c|c|c|c|c|c|c|c|c|}
\hline $\begin{array}{l}\text { M. paniculata } \\
\text { plant no. }\end{array}$ & $\begin{array}{l}\text { No. D. citri } \\
\text { on/off }{ }^{\mathbf{b}}\end{array}$ & $\begin{array}{c}\text { D. citri } \\
\text { post-IAP Ct }\end{array}$ & $\begin{array}{c}\text { Plant assay } 1 \\
\text { 2-month PI } \\
(\mathbf{C t})^{\mathrm{d}}\end{array}$ & $\begin{array}{c}\text { Plant assay } 2 \\
\text { 5-month PI } \\
(\mathbf{C t})^{\mathrm{e}}\end{array}$ & $\begin{array}{c}\text { Plant assay } 3 \\
\text { 10-month PI } \\
\text { (Ct) }\end{array}$ & $\begin{array}{l}\text { Plant assay } 4 \\
\text { 18-month PI } \\
\text { (Ct) }\end{array}$ & $\begin{array}{l}\text { Plant assay } 5 \\
\text { 24-month PI } \\
\text { (Ct) }\end{array}$ & $\begin{array}{c}\text { Plant assay } 6 \\
\text { 32-month PI } \\
\text { (Ct) }\end{array}$ \\
\hline 1 & $50 / 37$ & 31.4 & 35.2 & 36.8 & 45.2 & 0.0 & 0.0 & $0.0^{\mathrm{f}}$ \\
\hline 2 & $50 / 43$ & 36.4 & 33.4 & $\ldots$ & 0.0 & 37.1 & 0.0 & 33.3 \\
\hline 5 & $50 / 32$ & 36.3 & 32.0 & $\ldots$ & 31.8 & 0.0 & 0.0 & 36.8 \\
\hline 36 & $50 / 46$ & 17.3 & 35.9 & 38.1 & 0.0 & 0.0 & 0.0 & 0.0 \\
\hline
\end{tabular}

a Original individual $M$. paniculata plants from Table 1 .

${ }^{\text {b }}$ Number of $D$. citri transferred onto $M$. paniculata for 14 days/number of $D$. citri psyllids surviving after 14 days.

${ }^{c}$ Real-time polymerase chain reaction (PCR) cycle threshold (Ct) value for D. citri following 14-day inoculation access period (IAP) on M. paniculata.

${ }^{\mathrm{d}}$ Real-time PCR assay of M. paniculata 2 months postinoculation (PI).

e $\ldots=$ No real-time PCR assay data point.

${ }^{\mathrm{f}}$ Real-time PCR assay of M. paniculata 2 months post reinoculation by ' $\mathrm{Ca}$. Liberibacter asiaticus' at 30 months; 32 months after original inoculation. 
asiaticus' ITS region from the four plants that tested positive by real-time PCR failed, and the presence of ' $\mathrm{Ca}$. L. asiaticus' could not be confirmed by sequencing.

M. exotica inoculations. Twenty-one of the $23 \mathrm{M}$. exotica tested positive for the Taiwan isolate following psyllid inoculation as previously described, with $\mathrm{Ct}$ values ranging from 33.1 to 40.2 (mean 36.2, Table 4). Seven months after inoculation, only five of the $21 \mathrm{M}$. exotica remained positive by PCR (Table 4). Two M. exotica plants (\#2 [Ct 35.0] and \#13 [Ct 33.1])
(Table 4) were confirmed as ' $C a$. L. asiaticus'-positive by cloning and sequencing of the ITS region.

' $\mathrm{Ca}$. L. asiaticus' back-inoculations to sweet orange. Ten of the $M$. paniculata plants inoculated with either the Taiwan or Florida isolate of ' $\mathrm{Ca}$. L. asiaticus', all of which exhibited $\mathrm{Ct}$ values less than 36 , were used for back-assay inoculations to sweet orange (Table 5). Psyllids surviving the IAP on sweet orange were tested by PCR for the presence of ' $\mathrm{Ca}$. L. asiaticus', and $\mathrm{Ct}$ values were comparable to those following the AAP on Murraya. In all

Table 4. Reaction of Murraya exotica to inoculation with 'Candidatus Liberibacter asiaticus' following vector transmission by Diaphorina citri

\begin{tabular}{ccccc}
\hline Plant no. & $\begin{array}{c}\text { No. } \boldsymbol{D} \text {. citri } \\
\text { on/off }^{\mathbf{a}}\end{array}$ & $\begin{array}{c}\text { D. } \text { citri } \\
\text { post-IAP }(\mathbf{C t})^{\mathbf{b}}\end{array}$ & $\begin{array}{c}\text { Plant } \\
\text { 3-month PI (Ct) })^{\mathbf{c}}\end{array}$ & $\begin{array}{c}\text { Plant } \\
\text { 7-month PI (Ct) }\end{array}$ \\
\hline 1 & $50 / 15$ & 19.6 & 35.0 & 0.0 \\
2 & $50 / 26$ & 19.2 & 33.6 & 0.0 \\
3 & $50 / 40$ & 24.1 & 34.9 & 0.0 \\
4 & $50 / 19$ & 24.3 & 34.9 & 0.0 \\
5 & $50 / 8$ & 21.7 & 35.8 & 0.0 \\
6 & $50 / 33$ & 21.1 & 35.8 & 0.0 \\
7 & $50 / 32$ & 20.6 & 36.5 & 0.0 \\
8 & $50 / 28$ & 32.4 & 34.1 & 0.0 \\
9 & $50 / 29$ & 21.1 & 38.9 & 0.0 \\
10 & $50 / 23$ & 30.0 & 35.4 & 0.0 \\
11 & $50 / 9$ & 23.0 & 38.6 & 0.0 \\
12 & $50 / 9$ & 19.9 & 36.8 & 0.0 \\
13 & $50 / 9$ & 22.4 & 33.1 & 0.0 \\
14 & $50 / 40$ & 33.4 & 36.7 & 0.0 \\
15 & $50 / 45$ & 33.3 & 35.9 & 0.0 \\
16 & $50 / 35$ & 36.9 & 37.8 & 0.0 \\
17 & $50 / 35$ & 32.6 & 35.4 & 0.0 \\
18 & $50 / 35$ & 34.7 & 37.1 & 0.0 \\
19 & $50 / 35$ & 35.7 & 40.2 & 0.0 \\
20 & $50 / 24$ & 34.6 & 38.5 & 0.0 \\
21 & $50 / 41$ & 28.4 & 36.2 & 0.0 \\
22 & $50 / 12$ & 31.1 & 0.0 & 39.6 \\
23 & $50 / 18$ & 21.4 & 0.0 & 0.0 \\
\hline
\end{tabular}

a Number of $D$. citri transferred onto $M$. exotica for 14-day inoculation access period (IAP)/number of D. citri surviving after 14 days.

${ }^{\text {b }}$ Real-time polymerase chain reaction (PCR) assay of D. citri following 14-day IAP on M. exotica.

${ }^{c}$ Real-time PCR assay of M. exotica 3 months postinoculation (PI).

Table 5. Back-inoculations of 'Candidatus Liberibacter asiaticus' from infected Murraya paniculata to Madam Vinous sweet orange following vector transmission by Diaphorina citri

\begin{tabular}{|c|c|c|c|c|c|}
\hline $\begin{array}{l}\text { M. paniculata } \\
\text { plant no. } / \mathbf{C t}^{\mathrm{b}}\end{array}$ & $\begin{array}{c}\text { No. D. citri } \\
\text { on/off }\end{array}$ & $\begin{array}{c}\text { D. citri } \\
\text { post-AAP }(C t)^{d}\end{array}$ & $\begin{array}{c}\text { Sweet orange } \\
3 \text { month PI } \\
(\mathrm{Ct})^{\mathrm{e}}\end{array}$ & $\begin{array}{l}\text { Sweet orange } \\
22 \text { month PI } \\
\text { (Ct) }\end{array}$ & $\begin{array}{c}\text { Sweet orange } \\
\text { symptoms }\end{array}$ \\
\hline $2 /(33.4)$ & $40 / 27$ & 23.2 & 23.1 & 21.1 & $\begin{array}{l}\text { Blotchy mottle, } \\
\text { corky veins }\end{array}$ \\
\hline $3 /(34.8)$ & $40 / 17$ & 32.4 & 23.2 & 22.1 & $\begin{array}{l}\text { Blotchy mottle, } \\
\text { corky veins }\end{array}$ \\
\hline $4 /(32.8)$ & $40 / 24$ & 39.1 & 0.0 & 0.0 & No symptoms \\
\hline $10 /(34.5)$ & $40 / 34$ & 39.2 & 38.4 & 0.0 & No symptoms \\
\hline $11 /(34.9)$ & $40 / 38$ & 34.8 & 38.5 & 38.7 & No symptoms \\
\hline$* 13 /(29.1)$ & $40 / 38$ & 31.4 & 36.8 & 41.0 & No symptoms \\
\hline$* 15 /(32.7)$ & $40 / 31$ & $\ldots^{\mathrm{f}}$ & 38.8 & 0.0 & No symptoms \\
\hline$* 17 /(32.6)$ & $40 / 36$ & $\ldots$ & 32.3 & $\ldots$ & No symptoms \\
\hline *18/(32.9) & $40 / 33$ & $\ldots$ & 38.8 & $\ldots$ & No symptoms \\
\hline$* 19 /(31.2)$ & $40 / 30$ & $\ldots$ & 39.9 & 0.0 & No symptoms \\
\hline
\end{tabular}

${ }^{a}$ Individual M. paniculata plants from Table 1 with original first polymerase chain reaction (PCR) assay cycle threshold $(\mathrm{Ct})$ value.

b Plants without * inoculated with Taiwan B239, plants with * inoculated with FL 10210.

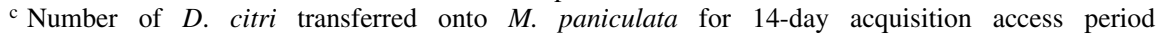
(AAP)/surviving $D$. citri after 14 days.

${ }^{\mathrm{d}}$ Real-time PCR assay of D. citri following AAP on M. paniculata.

e Real-time PCR assay of M. paniculata 3 months postinoculation (PI).

${ }^{\mathrm{f}}$ No real-time PCR assay data point. inoculation trials, there was considerable variability in $\mathrm{Ct}$ levels among the psyllids. Back-inoculations from two $M$. paniculata plants resulted in sweet orange test plants clearly symptomatic of HLB and with correspondingly low $\mathrm{Ct}$ values. Seven sweet orange plants had $\mathrm{Ct}$ values between 32 and 39, with no HLB symptoms after 22 months, and one back-assay was negative (Table 5). Symptoms in the backinoculated sweet oranges were directly correlated with PCR values for ' $C a$. L. asiaticus'. Orange plants with $\mathrm{Ct}$ values less than 30 in this experiment demonstrated typical HLB symptoms, while plants with $\mathrm{Ct}$ values above 30 had no symptoms (Table 5). This was consistent with observations of symptoms in sweet orange positive controls from the original experiments.

\section{DISCUSSION}

$M$. paniculata is a commonly grown ornamental in tropical and subtropical areas. The plant is widely grown in southern Florida and is known to be colonized by Asian citrus psyllids. Reports of the association between Asian citrus psyllids, Murraya, and HLB are common in literature with regard to the epidemiology of the disease $(8,14,15)$. However, a clear demonstration of the role of Murraya spp. as hosts from natural infections is lacking, and this is further confounded by conflicting statements on taxonomy of the species. Considering the value of reservoir host removal in attempts to control HLB in Florida, a clear understanding of how ' $\mathrm{Ca}$. Liberibacter' spp. interact with these important ornamentals is needed.

When experimentally inoculated with psyllids, $M$. paniculata seedlings became infected with ' $\mathrm{Ca}$. L. asiaticus' isolates from Taiwan and from Florida, but symptoms were either weak or not diagnostic. Symptoms were not the yellowing or blotchy mottle seen with HLB disease on citrus. M. exotica (which may actually be a variety of $M$. paniculata) also served as a host of ' $\mathrm{Ca}$. L. asiaticus' with no recognizable symptoms. However, the infections in $M$. exotica resulted in lower mean levels of ' $C a$. L. asiaticus' (based on higher Ct values in real-time PCR) than occurred with infected $M$. paniculata, and the presence of ' $C a$. L. asiaticus' was not detected by realtime PCR after 9 months, suggesting it did not persist. Infections, transient in nature, were systemic and could be detected in newly forming leaves. Infections in both the M. paniculata and $M$. exotica were confirmed using two different PCR primer sets (only the HLBAsia results are shown) and by sequencing and analyzing the PCR products and blasting them against ITS regions published in GenBank.

Results from $B$. koenigii inoculations were less definitive. Initial PCR tests indicated four infected plants out of 17 inoculated. However, attempts to confirm the 
presence of ' $\mathrm{Ca}$. L. asiaticus' using two different primer combinations and/or sequencing were negative. This suggests that the original PCR results were false positives. No attempt was made to backinoculate sweet orange seedlings from the B. koenigii plants that initially had $\mathrm{Ct}$ values under 35 because all plants tested negative within a short time postinoculation and no PCR products typical of ' $\mathrm{Ca}$. L. asiaticus' could be sequenced. Our data suggest that $B$. koenigii is not a host for 'Ca. L. asiaticus'.

For a plant species to serve as an inoculum reservoir, it should retain the pathogen in an infectious state over an extended period of time. In order to determine the potential of M. paniculata and M. exotica to serve as reservoirs for ' $\mathrm{Ca}$. L. asiaticus', the plants that tested positive were maintained for up to 32 months and periodically assayed by PCR for the presence of the bacterium. Infected $M$. paniculata plants remained positive for several months, and most of the plants with initial good ' $\mathrm{Ca}$. L. asiaticus' levels ( $\mathrm{Ct}$ values below 32) remained positive at least 10 months. However, within 18 months, nearly all $M$. paniculata plants were considered negative on the basis of PCR analysis. This suggests that ' $\mathrm{Ca}$. L. asiaticus' either was not multiplying at a rate equal to plant growth, or that $M$. paniculata is not a good reservoir host. Four $M$. paniculata plants that were initially PCR positive but were determined to be negative within 18 months PI were reinoculated using $D$. citri. Evidence for reinfection was noted by PCR assay 2 months after inoculation (Table 2), which suggests that $M$. paniculata did not develop a systemic resistance response against the pathogen. Infected $M$. exotica were even less likely to sustain detectable levels of ' $C a$. L. asiaticus'. All the initially infected M. exotica plants, with one exception, were negative within 7 months PI, regardless of initial levels of ' $\mathrm{Ca}$. L. asiaticus'.

Ten infected $M$. paniculata plants were tested for their ability to serve as an inoculum source, a true indicator of reservoir status. At 2 months PI, healthy psyllids were able to acquire and transmit ' $\mathrm{Ca}$. L. asiaticus' from infected Murraya plants to sweet orange. The success of backinoculation did not always coincide with the ' $C a$. L. asiaticus' level in the source plants as determined by $\mathrm{Ct}$ value, and it is interesting to note that individual plants with $\mathrm{Ct}$ values as high as 34.9 were capable of serving as a source for successful back-inoculation to orange. These data confirm that $M$. paniculata can serve as a reservoir for ' $\mathrm{Ca}$. L. asiaticus'. No attempt at back-inoculation was made using infected $M$. exotica as a source because of the rapid decline of detectable bacteria in this host. However, we assume that $M$. exotica plants with ' $\mathrm{Ca}$. L. asiaticus' levels similar to those of $M$. paniculata plants would be able to function as short-term reservoirs for successful back-inoculation, especially since PCR product was sequenced from two different $M$. exotica plants.

As a result of controlled inoculation experiments with two Asiatic isolates of ' $\mathrm{Ca}$. L. asiaticus' using $D$. citri as vector, we conclude that while $M$. paniculata is an excellent host for colonizing the psyllid, it is variable as a reservoir host of the HLBassociated bacterium. Both M. paniculata and $M$. exotica could serve as bridging hosts if more susceptible Citrus species are present, but based on our evidence that ' $C a$. L. asiaticus' levels become extremely low in Murraya after 5 months, if Citrus plants are unavailable during that time, Murraya species are likely to be unimportant as hosts. The most critical epidemiological contribution by Murraya species growing near ' $C a$. L. asiaticus'-infected Citrus would be the large numbers of $D$. citri available as vectors moving between the Murraya species and infected and healthy Citrus plants.

\section{ACKNOWLEDGMENTS}

We acknowledge the excellent technical assistance of Diana Sherman in conducting laboratory assays, William Bruckart and Morris Bonde for critical review of the manuscript, John Hartung for supplying HLB source plants, and Susan Halbert for the original identification of Diaphorina citri used in these experiments.

\section{LITERATURE CITED}

1. Anonymous. 2008. Asian citrus psyllid \& Huanglongbing reported in Louisiana, "USDA-APHIS-PPQ 06/13/2008". Citrus Clonal Protection Program (CCPP) - Citrus News. http://ccpp.ucr.edu/

2. Anonymous. 2008. Memos: For Information and Action DA-2008-28 and DA-2008-53. Confirmation of Asian Citrus Psyllid in Tijuana, Mexico and Alabama, Georgia, Mississippi, and South Carolina, respectively. USDA, APHIS. http://www.aphis.usda.gov

3. Anonymous. 2009. ProMED-PLANT Digest. Vol. 2009: Number 072.

4. Anonymous. 2009. ProMED-PLANT Digest. Vol. 2009: Number 079.

5. Anonymous. 2009. ProMED-PLANT Digest. Vol. 2009: Number 121.

6. Anonymous. 2009. Huanglongbing, citrus Puerto Rico: 1st report. http://www.promed mail.org

7. Bové, J. M. 2006. Huanglongbing: A destructive, newly-emerging, century-old disease of citrus. J. Plant Pathol. 88:7-37.

8. Chakraborty, N. K., Pandey, P. K., Chatterjee, S. N., and Singh, A. B. 1976. Host preference in Diaphorina citri Kuwayama, vector of greening disease in India. Indian J. Entomol. 38:196-197.

9. da Graca, J. V. 1991. Citrus greening disease. Annu. Rev. Phytopathol. 29:109-136.

10. Davis, M. J., Mondal, S. N., Chen, H., Rogers, M. E., and Brlansky, R. H. 2008. Cocultivation of 'Candidatus Liberibacter asiaticus' with Actinobacteria from Citrus with Huanglongbing. Plant Dis. 92: 1547-1550.

11. French, J. V., Kahlke, C. J., and da Graca, J. V. 2001. First record of the Asian citrus psylla, Diaphorina citri Kuwayama (Homoptera: Psyllidae), in Texas. Subtrop. Plant Sci. 53:14-15.
12. Halbert, S. E. 1998. Entomology Section. Triology (May-June 1998) 37(3):6-7.

13. Halbert, S. 2005. The discovery of huanglongbing in Florida. Page 50 in: Proc. Int. Citrus Canker Huanglongbing Workshop, 2nd, Orlando, FL.

14. Halbert, S. E., and Manjunath, K. L. 2004. Asian citrus psyllids (Sternorrhyncha: Psyllidae) and greening disease of citrus: A literature review and assessment of risk in Florida. Fla. Entomol. 87:330-354.

15. Hall, D. 2008. Effects of freezes on survival of Diaphorina citri. Page 5 in: Proc. Int. Res. Conf. Huanglongbing.

16. Hung, T. H., Wu, M. L., and Su, H. J. 2000. Identification of alternative hosts of the fastidious bacterium causing citrus greening disease. J. Phytopathol. 148:321-326.

17. Husain, M. A., and Nath, L. D. 1927. The citrus psylla (Diaphorina citri, Kuw.) [Psyllidae:Homoptera]. Memior Dep. Agric. India, Ser. 10:5-27.

18. Integrated Taxonomic Information System. 2009. ITIS Report. http://www.itis.gov.

19. Jagoueix, S., Bové, J. M., and Garnier, M. 1997. Comparison of the $16 \mathrm{~S} / 23 \mathrm{~S}$ Ribosomal Intergenic Regions of "Candidatus Liberobacter asiaticum" and "Candidatus Liberobacter africanum", the two species associated with Citrus Huanglongbing (Greening) Disease. Int. J. Syst. Bacteriol. 47:224-227.

20. Li, W., Hartung, J. S., and Levy, L. 2006. Quantitative real-time PCR for detection and identification of Candidatus Liberibacter species associated with citrus huanglongbing. J. Microbiol. Methods 66:104-115.

21. Lima, A. M. Da C. 1942. Insectos do Brazil: Homopteros 3, Rio de Janeiro (Imprenso National). p. 101.

22. Lopes, S. A., Martins, E. C., and Frare, G. F. 2005. Deteccão de Candidatus Liberibacter americanus em Murraya paniculata. Sum. Phytopathol. 31:48-49.

23. Matos, L., Hilf, M. E., and Camejo, J. 2009. First report of 'Candidatus Liberibacter asiaticus' associated with Citrus Huanglongbing in the Dominican Republic. Plant Dis. 93:668.

24. Nair, K. N., and Nayar, M. P. 1997. Rutaceae In: The Flora of India. P. K. Hajra et al., eds. Botanical Survey of India. BSI, Calcutta (Kolkata). Vol. 4:259-408.

25. Ranade, S. A., Rana, T. S., Srivastava, A. P., and Nair, K. N. 2006. Molecular differentiation in Murraya ex L. species in India inferred through ITS, RAPD and DAMD analysis. Curr. Sci. 90:1253-1258.

26. Reinking, O. A. 1919. Diseases of economic plants in southern China. Philippine Agric. 8:109-135.

27. Sechler, A., Schuenzel, E. L., Cooke, P., Donnua, S., Thaveechai, N., Postnikova, E., Stone, A. L., Schneider, W. L., Damsteegt, V. D., and Schaad, N. W. 2009. Cultivation of 'Candidatus Liberibacter asiaticus', 'Ca. L. africanus', and ' $\mathrm{Ca}$. L. americanus' associated with Huanglongbing. Phytopathology 99:480-486.

28. Stone, B. C. 1985. Rutaceae. In: A Revised Handbook to the Flora of Ceylon. M. D. Dassanayake and F. R. Fosberg, eds. Amerind, New Delhi, India. Vol. 5:176-406.

29. Texeira, D. C., Ayres, J., Kitajima, E. W. Tanaka, F. A. O., Danet, L., JagoueixEveillard, S., Saillard, C., and Bové, J. M. 2005. First report of a Huanglongbing-like disease of citrus in São Paulo State, Brazil and association of a new Liberibacter species, "Candidatus Liberibacter americanus", with the disease. Plant Dis. 89:107.

30. Zhou, L. J., and Gabriel, D. W. 2007. First report of dodder transmission of Huanglongbing from naturally infected Murraya paniculata to citrus. Plant Dis. 91:227. 